\title{
TRIBOLOGICAL PROPERTIES OF STELLITE 6 COBALT ALLOY IMPLANTED WITH NITROGEN IONS DETERMINED IN THE TESTS CONDUCTED IN ENGINE FUEL ATMOSPHERE
}

\author{
Mariusz Kamiński', Piotr Budzyński \\ Faculty of Mechanical Engineering, Lublin University of Technology, Nadbystrzycka 36, 20-618 Lublin, Poland, \\ e-mail:m.kaminski@pollub.pl, p.budzynski@pollub.pl
}

Received: 2017.10.23

Accepted: 2017.11.01

Published: 2017.12.05

\begin{abstract}
The influence of nitrogen ion implantation on the tribological properties of Stellite 6 cobalt alloy was investigated. The tribological tests were conducted using a pin / ball on disc in the atmosphere of engine fuels. In the study, cobalt alloy was implanted with $60 \mathrm{keV}$ nitrogen ions at the fluence of $1 \cdot 10^{16}$ and $5 \cdot 10^{16} \mathrm{~N}^{+} / \mathrm{cm}^{2}$. The wear trace was measured using the Form Talysurf Intra Taylor Hobson profilometer. The results demonstrate that nitrogen ion implantation affects the friction coefficient and wear. The effect of nitrogen ion implantation depends on the environment in which the tribological test is carried out, the sample temperature and the presence of friction products in the friction node.
\end{abstract}

Keywords: Stellite 6, tribology, cobalt alloy, engine, automotive industry.

\section{INTRODUCTION}

Current trends in the automotive industry are aimed at achieving best-of-breed driving systems in vehicles. Combustion engines widely used in vehicles have to meet increasingly stringent exhaust gas quality and efficiency requirements. This necessitates the use of light and extremely durable materials in engine design. The efficiency of internal combustion engines depends on their capability to generate and maintain high pressure in the combustion chamber. Besides the pistonring-cylinder system, valves and valve seats are largely responsible for tightness of the combustion chamber. They are elements of valve timing in four-stroke engines designed to facilitate the supply of fresh air or the air-fuel mixture to the cylinder; next, they have to ensure tightness during compression and combustion of the load, and to facilitate the removal of exhaust gas from the cylinder [17].

The environment in which engine valves operate generates a variety of loads. The valves and valve seats are exposed to direct contact with high temperature while sealing the combustion chamber and fuel flow around the valves and valve seats in the exhaust stroke [12]. Also, the work of the valves generates high mechanical loads associated with the impact of the surface of the valve heads against the surface of the valve seats. In addition, the exhaust valves exhibit high thermal conductivity, heat resistance, low thermal expansion coefficient, and low resistance to tribological wear and corrosion [14].

The damage of valve seat surfaces causes losses of pressure in the combustion chamber, which results in decreased efficiency of the internal combustion engine. To prevent their rapid wear, the valves and valve seats are made of materials that are resistant to substantial changes in temperature and to cyclic impact loads related to valve opening and closure. The intake valves are usually made of low alloy steels or chromium steels in the case of highly loaded engines. In turn, the exhaust valves are produced from various types of steel, e.g. ferritic-pearlitic, austenitic, and silchrome steels. Given the relatively low hardness of the valves and valve faces made of austenitic 
steels, their strength is improved by hardfacing [3], with stellite as the main welding material [2].

The name "stellite" denotes cobalt alloys. These alloys are resistant to abrasion and organic acids; they are also creep-resistant and heatresistant materials [3]. They are widely used in aviation, space, and automotive technologies as well as in biomedical engineering as implant materials. Stellites are used for producing the highest quality tools, combustion engine parts and other elements operating under extreme heat conditions. The alloy was developed in the early twentieth century and its mechanical properties are still being improved.

The strength properties of stellite-welded valve faces and valve seats can be improved using ion implantation. This process facilitates the implantation of ions of any element into the structure of materials, which changes their tribological $[6,11]$, chemical $[1,13,21]$, and mechanical properties. There are many well-known examples of improving material properties by the application of ion implantation; they are described e.g. in $[8,9,18,20]$. A great advantage is the negligible effect of ion implantation on the dimensions of a treated element; hence, the process can be applied in the final stage of manufacturing products that already have their final dimensions [4].

Besides the improvement of tribological properties, ion implantation contributes to increasing mechanical strength. This is associated with an increase in the microhardness of the implanted element. The implantation process is accompanied by the occurrence of compressive stresses and inclusions of nitrides, carbides, and borides. The implantation-induced hardening process depends on the type and dose of implanted ions and the temperature of implanted material $[10,19]$. It has been proven that the increase in the microhardness of the implanted material is a permanent change, retained even in the heating process [14]. Previous studies have shown that the ion implantation has a positive effect on the microhardness of cobalt steel Stellite 6 [5].

This aim of this paper is to determine whether the implantation of nitrogen ions will positively affect the tribological properties of Stellite 6 cobalt steel during a tribological test conducted in the atmosphere of a selected motor fuel such as Gasoline 95. Due to the fact that in indirect fuel injection the intake valves operate in the presence of fuel on the valve seat, it was considered reasonable to determine the effect of nitrogen ion implantation on the wear in fuel atmosphere.

\section{CHARACTERISTICS OF THE MATERIAL AND RESEARCH METHODOLOGY}

Given the multiple applications of stellite as a material for construction of valves and valve faces, this material was chosen for analysis and assessment. A commercial variety Stellite 6 was chosen. The alloy comprises $27-32 \% \mathrm{Cr}, 4-6 \%$ $\mathrm{W}$, and $0.9-1.4 \% \mathrm{C}$. The samples for the analyses were taken from a $25 \mathrm{~mm}$-diameter rod. The sample surfaces intended for the analysis were polished in order to achieve a roughness value of $\mathrm{Ra} \leq 0.01$.

The samples were subjected to the ion implantation process. Nitrogen was the implanted element. The implantation was performed evenly over the entire surface of the sample at the energy set to $65 \mathrm{keV}$. The dose of the implanted ions varied between the samples; the values of fluences of the implanted nitrogen ions are listed in Table 1.

The distribution of the implanted ions and radiations defects (vacancies) at equal sample depths was calculated with the use of SRIM program [21]. The measurements of friction and wear coefficients were carried out in a tribological test in friction conditions in gasoline 95 atmosphere on the Anton Paar Nano-Tribometer NTR2 (CFM Instrument). A tungsten carbide ball with a diameter of $0.5 \mathrm{~mm}$ and $1000 \mathrm{mN}$ contact force was used as a counter-sample.

The study was conducted in the presence of fuel to determine its effect on the friction and wear conditions of the implanted samples. Gasoline 95 was selected for the study because of its widespread use for otto engines characterized by indirect fuel injection. This results in the presence of fuel on the surface of valves that operate under friction conditions where the fuel is lubricated.

Next, the wear trace was measured using the Form Talysurf Intra Taylor-Hobson profile measurement gauge. The measurements of the obtained profilograms enabled determination of the mean wear of wear trace. The wear was defined as the mean surface of the cross section of contact between the sample and the counter-sample.

Table 1. Fluences of the implanted ions for individual samples

\begin{tabular}{|c|c|}
\hline Sample & $\begin{array}{c}\text { Fluences of implanted ions } \\
\left.\left[\mathrm{N}^{+} / \mathrm{cm}^{2}\right)\right]\end{array}$ \\
\hline S6.1 & $1 \cdot 10^{16}$ \\
\hline S6.2 & $5 \cdot 10^{16}$ \\
\hline S6.4 & unimplanted \\
\hline
\end{tabular}




\section{RESULTS AND DISCUSSION}

For the purpose of preliminary determination of ion-implantation, a numerical simulation was performed. Typically, numerical simulation results correspond well with experimental findings. Figure 1 presents a calculated (predicted) distribution of nitrogen ions implanted at an energy E set to $65 \mathrm{keV}$ and a fluence of $\mathrm{D}=1 \cdot 10^{16} \mathrm{~N}^{+} /$ $\mathrm{cm}^{2}$ into a cobalt alloy and vacancies generated thereby. The results demonstrate that the calculated range of the implanted nitrogen ions that does not exceed $0.17 \mu \mathrm{m}$ and the maximum concentration of vacancies occurs at a depth of $\sim 0.05 \mu \mathrm{m}$.

The results of the measurements of the friction coefficient are shown in Figure 2. When measuring the friction coefficient during a tribological test in the presence of a lubricant there is no such a great difference between the implanted and nonimplanted samples compared to technically dry friction conditions [7]. Compared to the sample that has not been subjected to ion implantation, a slight increase in the friction coefficient for the implanted samples is observed.

The mean value of the cross-sectional area of the track calculated from 20 measured profilograms was adopted as a measure of wear. Selected results of the wear tracks are shown in Figure 3.

A comparison between the wear test results shown in Figure 4 and the results of technically dry friction tests shown in Figue 5 reveals that the difference in wear of the implanted and unimplanted samples is not significant. However, the wear resistance of the ion implanted samples does not decrease during the tribological test in gasoline 95.

One can observe differences between the tribological results obtained at the friction node for the samples and counter samples immersed in the engine fuel (gasoline 95) and for those exposed to air atmosphere. The effect of lowering the friction and wear coefficients after im-

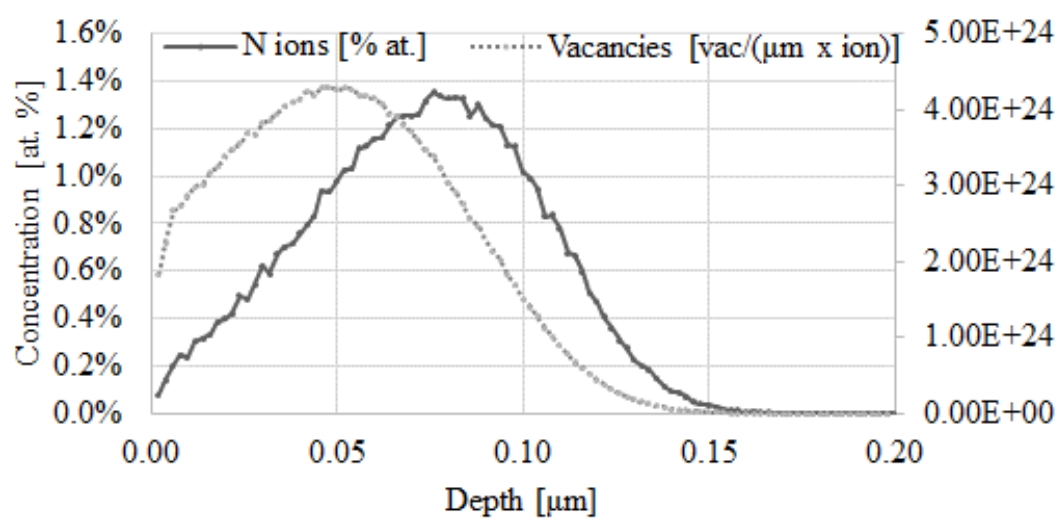

Fig. 1. Calculated distribution of nitrogen ions implanted at energy $E=65 \mathrm{keV}$ and fluence $\mathrm{D}=1 \cdot 10^{16} \mathrm{~N}^{+} / \mathrm{cm}^{2}$ into Stellite 6 cobalt alloy and gaps generated thereby

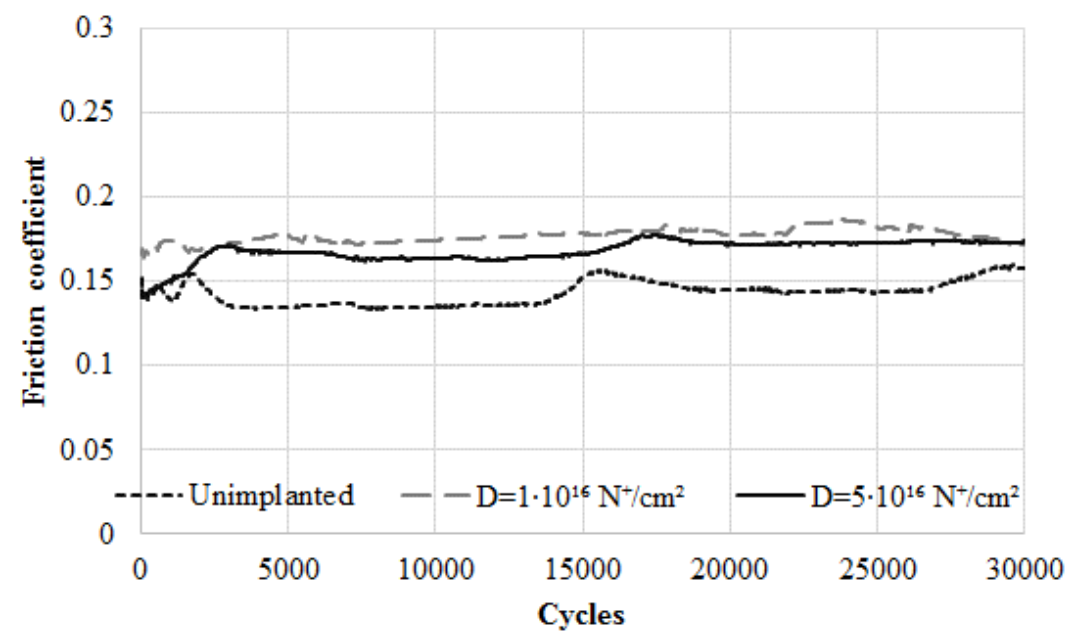

Fig. 2. Friction coefficient of Stellite 6 before and after implantation of nitrogen ions 

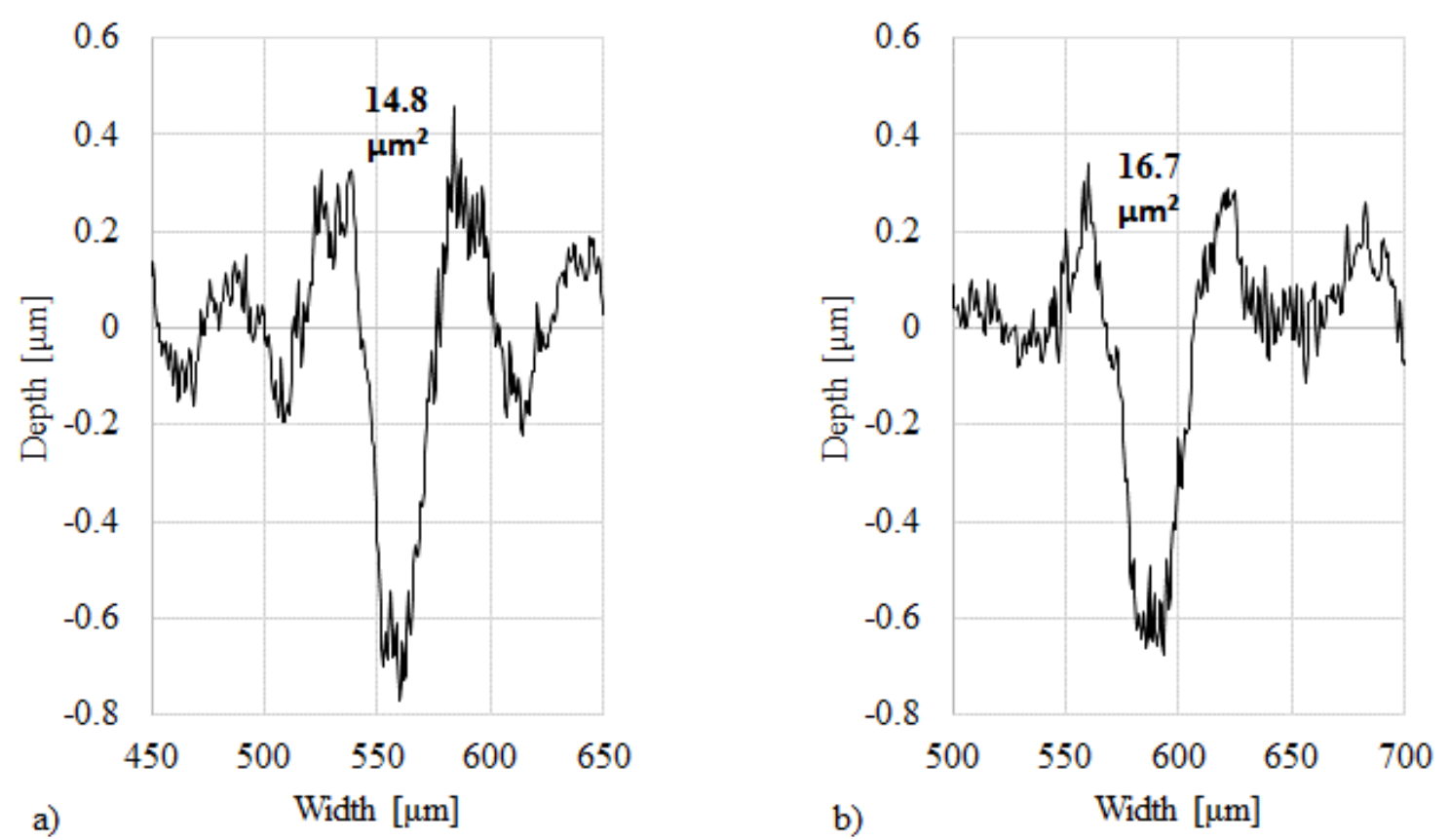

Fig. 3. Wear track profilograms of: a) unimplanted sample; b) implanted Stellite 6 sample with $D=1 \cdot 10^{16} \mathrm{~N}^{+} / \mathrm{cm}^{2}$

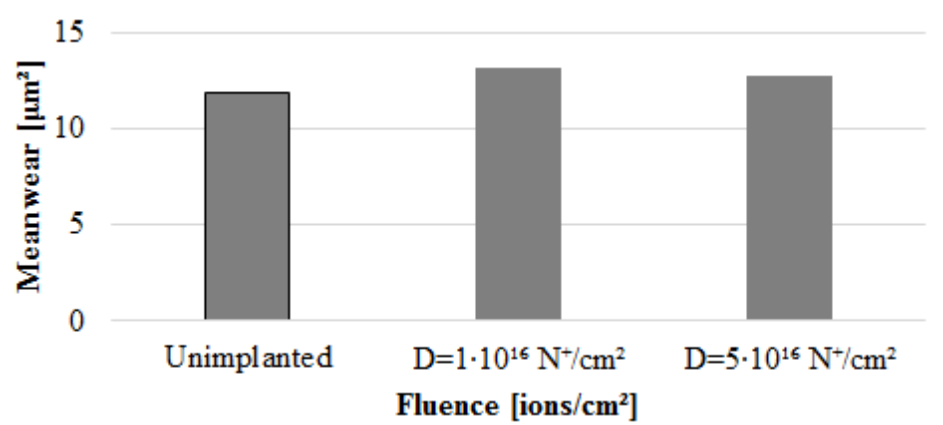

Fig. 4. Mean sample wear after 30000 measurement cycles in gasoline 95 atmosphere

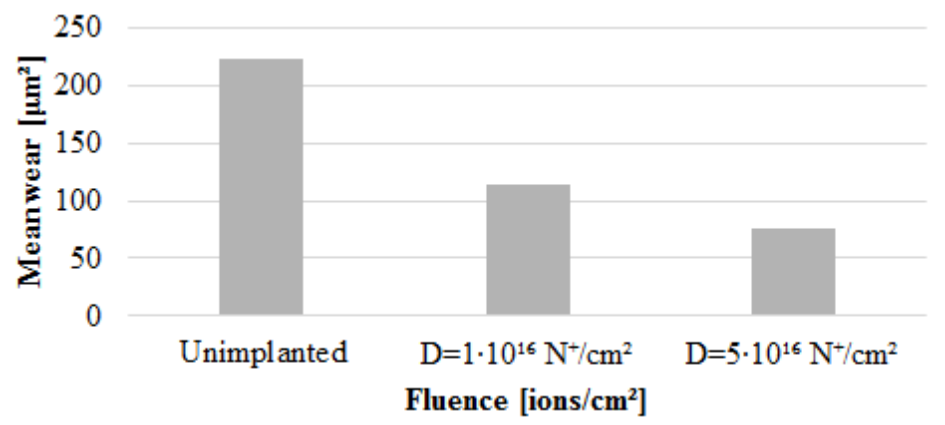

Fig. 5. Mean sample wear after 5000 measurement cycles in dry friction conditions [7]

plantation observed in the previous work [7] disappears. This can be caused by a lower local friction node temperature due to engine fuel overrun, which reduces the diffusion of nitrogen atoms and the speed of radiation defects moving into the sample. The sample and counter sample are more heavily cooled by the engine fuel than by the air. This leads to the disappearance of the long-range effect. In addition, during the test performed in motor fuel environment, the wear products remain at the friction node, smoothing the surface roughness and resulting in lower friction coefficients. This fact is confirmed by an increase in the friction coefficient to $15.000 \mathrm{cy}$ cles when the amount of fuel was increased after its partial evaporation. As was later observed, the friction coefficient always increases after adding fresh fuel. The fuel feed causes a temporary increase in the temperature of the friction node, thus increasing the friction coefficient. 


\section{CONCLUSIONS}

The friction coefficient of Stellite 6 cobalt alloy after ion implantation depends on the environment in which the tribological test (gasoline 95 or air atmosphere) is performed and on the removal rate of wear products from the friction node. As regards the gasoline 95 tests, the differences in the friction coefficient and tribological wear of implanted and unimplanted samples are small. In actual internal combustion engines, the inlet and outlet valves will operate at temperatures ranging $200-600^{\circ} \mathrm{C}$. This will probably lead to their lower consumption than in laboratory tests because of a higher working temperature that accelerates the diffusion of nitrogen and causes the radiation defects to move into the material, which will result in reduced wear of the implanted layer. In addition to the inlet valves, despite the presence of fuel on the surface of their seats, there occurs mixed friction - with the advantage of technically dry friction, for which a significant reduction in the friction coefficient and wear was achieved [7]. Preparations for such in-service research have already begun.

\section{REFERENCES}

1. Abreu C.M., Cristobal M.J., Figueroa R., Pena G.: Wear and corrosion performance of two different tempers (T6 and T73) of AA7075 aluminum alloy after nitrogen implantation, 2015, 327, 51-61.

2. Adamiec P., Dziubiński J.: Wybrane zagadnienia materiałów kontrukcyjnych i technologii wytwarzania pojazdów. WPŚ, Gliwice 1998.

3. Adamiec P., Dziubiński J.: Wytwarzanie i właściwości warstw wierzchnich elementów maszyn transportowych. WPŚ, Gliwice 2005.

4. Budzyński P.: Problematyka tarcia i zużycia tworzyw implantowanych jonowo w technologii maszyn. WPL, Lublin 2010.

5. Budzyński P., Kamiński M., Pałka K., Droździel A., Wiertel M.: The influence of nitrogen ion implantation on microhardness of the Stellite 6 alloy. IOP Conf. Series: Materials Science and Engineering 2016, 148, 012046.

6. Budzyński P., Kamiński M., Pyszniak K.: The influence of nitrogen ion implantation on the tribological properties of piston rings made of Hardox and Raex steels. IOP Conf. Series: Materials Science and Engineering, 2016, 148, 012044.

7. Budzyński P., Kamiński M., Wiertel M., Pyszniak K., Droździel A.: Mechanical properties of Stellite 6 cobalt alloy implanted with nitrogen ions. XI-th International Conference Ion Implantation and Other Applications of Ions and Electrons (ION 2016). 2016, 45.

8. Budzyński P., Kara L., Küçükömeroğlu T., Kamiński M.: The influence of nitrogen implantation on tribological properties of AISI H11 steel. Vacuum, 2015, 122, 230-235.

9. Budzyński P., Tarkowski P., Penkała P.: Influence of nitrogen ion implantation on tribological properties of tool steel NC10. Vacuum, 2001, 63, 731-736

10. Burakowski T., Wierzchoń T.: Inżynieria powierzchni metali. WNT, Warszawa 1995.

11. Cristobal M.J., Figueroa R., Mera L., Pena G.: Tribological behavior of aluminum alloy AA7075 after ion implantation, Surface Coatings and Technology, 2012, 209, 124-130.

12. Guo Z., Pang X., Yan Y., Gao K., Volinsky A. A., Zhang T. Y.: CoCrMo alloy for orthopedic Implant application enhanced corrosion and tribocorrosion properties by nitrogen ion implantation. Applied surface science. 2015, 347, 23-34.

13. Lewis R., Dwyer-Joyce R. S.: Wear of diesel engine inlet valves and seat inserts Proceedings of the Institution of Mechanical Engineers, Part D: Journal of Automobile Engineering, 2002, 216, 205-16

14. McCafferty E.: Effect of Ion Implantation on the corrosion behavior of iron, Stainless steels, and aluminum - a review, Corrosion, 2001, 57, 471-476.

15. Moćko W.: Analiza wytężenia zaworu silnikowego wykonanego ze stopu tytanu Ti6AL4V obciążonego mechanicznie i cieplnie Transport samochodowy, 2014, 4, 55-71.

16. Picard S., Memet J. B., Sabot R., Grosseau-Poussard J.L., Rivière J. P., Meilland R.: Corrosion behaviour, microhardness and surface characterisation of low energy, high current on implanted austenitic stainless steel. Mater. Sci. Engin., 2001, 303, 163-72.

17. Wajand J. A., Wajand J. T.: 2005 Tłokowe silniki spalinowe średnio- i szybkoobrotowe. WNT, Warszawa, 2005.

18. Wang F., Zhou Ch., Zheng L., Zhang H.: Corrosion resistance of carbon ion-implanted M50 NiL aerospace bearinh steel. Progress in Natural Science: Materials International, 2017, 27, 615-621.

19. Vlcak P., Cerny F., Drahokoupil J., Sepitka J., Tolbe Z.: The microhardness ond surface hardness of Ti6Al4V alloy implanted with nitrogen ions at an elevated temperature, 2015, 620, 48-54.

20. Zhang J., Peng S., Zhang A. et al.: Nitrogen ion implantation on the mechanical properties of AISI 420 martensitic stainless steel. Surface and Coating Technology, 2016, 305, 132-138.

21. Ziegler J. F.: SRIM-2003 steel Nuclear Instruments and Methods in Physics Research Section B: Beam Interactions with Materials and Atoms. 2004, 219-220, 1027-36. 